\title{
Should Minors Be Considered as Potential Living Liver Donors?
}

\author{
Laura Capitaine, ${ }^{1}$ Kristof Thys, ${ }^{2}$ Kristof Van Assche, $^{3}$ Sigrid Sterckx, ${ }^{1,3}$ and Guido Pennings ${ }^{1}$ \\ ${ }^{1}$ Bioethics Institute Ghent, Ghent University, Ghent, Belgium; ${ }^{2}$ Centre for Biomedical Ethics and Law, KU \\ Leuven, Flanders, Belgium; and ${ }^{3}$ Research Group on Law, Science, Technology, and Society, Vrije \\ Universiteit Brussel, Brussels, Belgium
}

\begin{abstract}
For many patients, living donor liver transplantation represents their only hope of receiving a lifesaving graft. In certain (albeit rare) cases, a minor will be the only suitable donor. Living liver donation by minors has been reported in several countries. In the academic literature and professional guidelines, little attention is paid to the development of an ethical framework for this practice. The focus is frequently limited to the donation of regenerative tissues and kidneys. However, liver donation differs in important respects because of the increased medical risks and the lack of substitute therapies. Therefore, in this article, we assess whether living liver donation by minors is ethically appropriate. We argue that living liver donation by minors is justifiable only if minors possess the capacity to consent to donation or if the procedure is in their best interests. Although minors may possess adult-like levels of cognitive maturity, they lack sufficient psychosocial maturity to give valid consent to donation. In addition, living liver donation is generally not in a minor's best interests. With respect to the latter, the potential psychological benefits that a minor may experience as a result of living liver donation are insufficiently empirically supported and are unlikely to outweigh the short- and long-term medical and psychological risks. Therefore, we conclude that minors should not be considered as potential living liver donors. Liver Transpl 19:649-655, 2013. (c) 2013 AASLD.
\end{abstract}

Received October 23, 2012; accepted February 24, 2013.

Living donor liver transplantation was successfully introduced in 1989 as a response to the exceptionally high waiting-list mortality rate for small children. ${ }^{1}$ Soon, the procedure was expanded to large adolescents and adults, and it has since become a widespread medical treatment for end-stage liver disease and genetic metabolic disorders. However, living liver donation involves a very complicated surgical procedure with a significant risk of mortality and morbidity. In the absence of worldwide registration and mandatory reporting, the exact estimation of donor mortality is extremely difficult. According to the most frequently cited estimates, mortality approaches $0.1 \%$ for left lobe donation and $0.5 \%$ for right lobe donation. ${ }^{2-4}$ As a result of widely diverging definitions, the incidence of donor morbidity is also of uncertain magnitude. ${ }^{5,6}$ Apart from the risk of general anesthesia, potentially serious morbidities include surgical site infections, biliary complications, portal vein thrombosis, intra- abdominal bleeding, pulmonary emboli, and incisional hernias. Studies focusing on such serious complications report an overall incidence rate of $15 \%$ to $20 \%{ }^{3,5,7-9}$

With these risks, the enormous benefit to the recipient is presumably the reason that living donor liver transplantation is still being performed. Obtaining an organ from a living donor may be the last resort for patients suffering from life-threatening liver disease. The need for liver transplantation is often more urgent than the need for kidney transplantation because the annual mortality rate for patients awaiting a liver graft is almost double that recorded for patients awaiting a kidney. In addition, liver donation cannot be postponed in the same way that kidney donation can be because there is no substitute treatment similar to hemodialysis and peritoneal dialysis that can sustain functions until an organ becomes available. ${ }^{10}$ Moreover, deceased liver donation has its technical limits.

\footnotetext{
The research of both Laura Capitaine and Kristof Van Assche is funded by the Flemish Fund for Scientific Research.

Address reprint requests to Laura Capitaine, M.A., Bioethics Institute Ghent, Ghent University, Blandijnberg 2, 9000 Ghent, Belgium. Telephone: +32 926478 86; FAX: +32 926441 87; E-mail: laura.capitaine@ugent.be

DOI 10.1002/It.23633

View this article online at wileyonlinelibrary.com.

LIVER TRANSPLANTATION.DOI 10.1002/lt. Published on behalf of the American Association for the Study of Liver Diseases
} 
Admittedly, the practice of reduced size and split graft liver transplantation has increased the availability of donor grafts, yet these grafts may not be suitable for all patients.

Despite the availability of living donor liver transplantation as a lifesaving procedure, only a fairly small percentage of potential living donors may be suitable. ${ }^{11}$ People suffering from common medical conditions such as cardiovascular disease, diabetes, and hypertension will be ruled out, and smoking and obesity may also be considered relative contraindications to living donation. Sometimes, a minor may be the only suitable donor, especially in cases of acute liver failure. ${ }^{12}$ Although this circumstance is very rare, living liver donations by minors have been reported. Specifically, there have been 13 such cases in the United States. ${ }^{13}$ Other countries such as Japan and Brazil have also recorded cases of minor living liver donors. ${ }^{14,15}$ When it is deemed to involve acceptable risks to the health of the donor, living liver donation by minors is allowed in several other countries such as Ireland, Sweden, and the United Kingdom. Moreover, in countries that currently allow minors to donate only hematopoietic stem cells, a tendency could be developing to interpret the possibility for minors to donate regenerative tissue to also include liver segments or lobes. An indication hereof can be found in the August 2012 amendment of the Belgian transplantation law. ${ }^{16}$ The possibility for minors to donate regenerative tissue, which had previously been interpreted as pertaining only to hematopoietic stem cells, has now been reinterpreted to also refer to liver segments or lobes. This law allows minors as young as 12 years to donate to a brother or sister on the condition that they are capable of expressing their will and have given prior consent.

In the academic literature and professional guidelines, little attention is paid to developing a specific ethical framework for living liver donation by minors. The focus is frequently limited to the donation of regenerative tissues and kidneys. However, because of the increased medical risks of liver donation and the lack of substitute therapies, the considerations that are relevant in this context may differ in important respects from those pertaining to kidney and regenerative tissue donation. Thus, there is an urgent need for more profound reflection on the ethical aspects of living liver donation by minors. In this article, we try to assess whether living liver donation by minors can be ethically appropriate. We occasionally refer to the new Belgian law as a starting point for our ethical reflection.

\section{LIVING LIVER DONATION AND DECISIONAL CAPACITY}

The imposition of risks to the living liver donor may be warranted when the donor decides that the risks are worth taking. In other words, a potential living donor has a moral right to accept a considerable health risk in order to help a patient in need of an organ. ${ }^{17,18}$
However, the primacy of the donor's right to donate is not absolute. Most importantly, the decision to donate should be an autonomous one, and this implies that the potential donor demonstrates decisional capacity. A person possesses this capacity when he or she is able to comprehend and make a judgment about the information concerning a medical intervention, to intend a certain outcome, and to communicate freely his or her wishes. ${ }^{19}$

For subjects possessing decisional capacity, their prior free and informed consent is a necessary condition of morally permissible living liver donation. Disclosure, understanding, and voluntariness are generally recognized as the necessary components of informed consent. ${ }^{19}$ The disclosure factor implies that complete, objective, and intelligible information should be provided in order to allow the potential living liver donor to arrive at a well-reasoned conclusion. The understanding component requires one to ensure that the potential donor has an accurate understanding of the purpose and nature of the procedure, the possible consequences to his or her health and emotional well-being, the expected health impact on the recipient, and the availability and efficacy of possible alternative therapies. Finally, the voluntariness element requires screening aimed at verifying that potential living liver donors are not influenced by undue pressure, deception, or financial incentives. ${ }^{17,18}$

Except for adults who have been judicially declared mentally incompetent, the law operates under the rebuttable presumption that adults are competent to make their own decisions about living liver donation. However, even when a person is deemed sufficiently competent and free and informed consent to donate is obtained, the autonomy of the potential adult donor is still bound by legal restrictions and standards of reasonable medical practice. Donation will not be allowed when the transplant team is of the opinion that the overall risk-benefit balance of the procedure is clearly negative or that the absolute level of risk to the donor is too high. In addition, in most countries, living liver donation is subject to additional requirements, such as authorization by an independent body and restriction to recipients with whom a close personal relationship exists. These provisions are intended to prevent undue pressure or improper inducement to donate. ${ }^{17,18}$

If we are to determine whether minors should be allowed to donate a liver lobe, we must ascertain whether they possess sufficient capacity to make this decision. Therefore, in the following sections, we take a closer look at minors' decision-making capacity. First, we discuss the (exceptional) circumstances under which minors are considered legally competent to make their own health care decisions. Next, we develop a moral framework that provides a means of distinguishing those health care decisions that minors (of a certain age) are capable of making from those that they are incapable of making. Finally, we apply this moral framework to the specific context of living liver donation. 


\section{ASSESSING MINORS' COMPETENCE TO CONSENT TO MEDICAL INTERVENTIONS}

\section{Legal Framework}

Minors are legally considered as incompetents lacking the necessary capacity to make fully informed medical decisions. ${ }^{20}$ There is a general, legal presumption that parents have their children's best interests at heart. ${ }^{21}$ Parents, therefore, are granted the right to make health care decisions on their minor children's behalf. The requirement for parental consent in the medical care of minors is subject to 4 possible exceptions.

First, in emergency situations, when there is no time to obtain parental consent, medical personnel are allowed to treat a minor. The rationale behind this exception is the idea that parents, if present, would consent to treatment. In addition, the emergency exception serves to protect the physician from liability. ${ }^{22}$

Second, minors who are emancipated by marriage or other circumstances have the right to make decisions on their own behalf.

Third, many jurisdictions explicitly authorize minors to consent to certain specific medical interventions, such as prenatal care, drug treatment, contraception, mental health care, and testing and treatment for sexually transmitted diseases. This authorization aims to encourage minors to seek care that, under a parental consent requirement, might not be sought for fear of parental punishment. As such, this third exception primarily constitutes a protective measure for minors. ${ }^{20}$

A final exception to the parental consent requirement is the mature minor doctrine. This permits a minor to consent to or refuse treatment if he or she has the capacity to understand the nature and consequences of the medical decision at hand. Many countries appear to have adopted a mature minor doctrine of some sort. ${ }^{23,24}$ In the United States, however, only a few states have enacted statutes allowing mature minors to consent to their own medical treatment. ${ }^{22}$ In assessing a minor's level of maturity, courts take into account the nature and gravity of the treatment. Adolescents are generally found competent to consent to or refuse low-risk procedures (eg, tonsillectomies, vaccinations, and treatments for back pain), whereas they are seldom deemed sufficiently mature to consent to high-risk or life-altering procedures (eg, sex reassignment and sterilization). ${ }^{24}$ Moreover, with the exception of blood donation, courts do not generally sanction adolescent consent to nontherapeutic procedures benefiting a third party, such as skin graft donations. ${ }^{25}$ Courts vary with respect to the standard of proof used for determining maturity. Some have favored a case-by-case approach. Others have applied the rule of sevens, a standard derived from English common law. Under this rule, children under the age of 7 years do not have the capacity to consent, children who are 7 to 14 years old are presumed not to have this capacity (until proven otherwise in individual cases), and children over age 14 are presumed to have the capacity to make their own decisions (unless proven otherwise). ${ }^{26}$

\section{Moral Framework}

According to Steinberg and Scott, ${ }^{27}$ when we discuss decisional capacity, we should distinguish cognitive maturity from its psychosocial counterpart. Studies suggest that adolescents beyond the age of 14 years demonstrate a level of cognitive maturity similar to that of adults; that is, they possess adult-like capacities for logical reasoning about moral, social, and interpersonal matters. For example, a study by Weithorn and Campbell ${ }^{28}$ showed that 14-year-olds did not differ significantly from 18 - and 21-year-old adults with respect to their ability to reason or understand treatment information presented to them in medical dilemmas. Subsequent research into the development of cognitive capacities found similarly high levels of adolescent maturity (eg, Hale ${ }^{29}$ and Belter and Grisso $^{30}$ ). Those who advocate granting adolescents a higher degree of self-determination in medical decision making often cite this type of research. The American Psychological Association, for example, has argued for a recognition of adolescents' right to consent to abortion on the basis of their having decisionmaking skills comparable to those of adults. ${ }^{31}$

Although adolescents display cognitive capacities that come close to those of adults, they do not yet exhibit adult-like levels of psychosocial maturity. There are 4 psychosocial factors that are specifically relevant to decision-making outcomes. ${ }^{31}$

The first factor is susceptibility to social coercion. Research supports the common-sense view that adolescents are more susceptible to coercive influences than adults. ${ }^{32}$ In some contexts, adolescents' choices are made in response to direct peer pressure. However, adolescents' desire for peer approval or fear of rejection may also affect their choices indirectly (ie, in the absence of direct coercion).

Risk perception constitutes the second psychosocial factor. In comparison with adults, adolescents place less weight on risk in relation to reward. ${ }^{33}$ They often consider themselves invulnerable to harm. ${ }^{25}$ This factor, for example, explains why adolescents engage in unprotected sex more often than adults. The fact that adolescents demonstrate adult-like cognitive capacities implies that they are fully aware of and understand the potential risks involved. However, as a result of their distorted risk-reward calculus, they see the potential benefits of unprotected sex as outweighing the potential risks. ${ }^{34}$

The third psychosocial factor is known as future orientation, which refers to the extent to which one anticipates future consequences. Adolescents tend to focus mainly on the short-term consequences-both risks and benefits - of their choices, whereas adults also take into account long-term impacts (eg, Halpern-Felsher and Cauffman ${ }^{35}$ ). The limited life experience of adolescents may account for their greater 
inclination to discount the future: a result 10 years away from now is likely to appear more remote the shorter one's experienced lifespan is. ${ }^{36}$

The final psychosocial factor relates to impulsivity. Research indicates that adolescents are prone to more extreme mood swings and have more difficulty in controlling their impulses and behavior (eg, Farrington ${ }^{37}$ ).

The distinction between cognitive and psychosocial maturity provides us with a standard for identifying the type of decision to which the mature minor doctrine should be held applicable. In sum, it tells us which decisions we may allow adolescents to consent to or refuse. The established cognitive maturity of adolescents suggests that we should regard them as having sufficient decisional capacity to make health care decisions that are generally not strongly influenced by any of the aforementioned psychosocial factors. By contrast, their psychosocial immaturity implies that we ought to consider them as lacking the decisional capacity to make health care decisions with a strong psychosocial component, that is, decisions typically eliciting impulsivity and involving high levels of social coercion or significant immediate risks/longterm consequences. Note that it will not always be clear-cut whether one is dealing with a health care decision of the former or latter type.

One might argue that our approach is problematic in that it is based on findings of (in)sufficient decisional capacity in the average adolescent and thereby ignores possible deviations from the average. Admittedly, our approach runs the risk of assuming cognitive maturity where there is none and vice versa for psychosocial maturity. However, we currently lack the instruments to reliably assess maturity on an individualized basis. ${ }^{38}$ In the absence of such instruments, it seems unproblematic to presume that sufficient decisional capacity is present in the case of health care decisions in which psychosocial factors are not strongly at play. The latter, after all, tend to be lowrisk decisions. In the same vein, the typically highrisk nature of health care decisions with a strong psychosocial component suggests that in such cases we would do well to err on the side of insufficient decisional capacity.

\section{ASSESSING MINORS' CAPACITY TO CONSENT TO LIVING LIVER DONATION}

If we are to determine whether we should consider adolescents as having the capacity to consent to living liver donation, we must identify the type of decisionmaking process involved. Therefore, this section will examine for each of the psychosocial factors the extent to which they are relevant to the context of living liver donation by minors.

With respect to susceptibility to social coercion, it should be noted that the context of living donation exhibits certain features that increase the chances of coercive pressures occurring. One such feature is that donation typically takes place between family members. In the case of living liver donation, there is the added element of the lack of any substitute therapy. Parents, regardless of whether they themselves or one of their children is in need of a liver, may pressurize their minor child into donation. The minor is likely to succumb to such pressure because he or she is socially dependent on his or her parents. If the candidate recipient is a sibling, the latter may exert an additional source of coercion, especially if he or she is an adult.

The psychosocial factor of risk perception is also highly relevant to the context of living liver donation by minors. As noted earlier, living liver donation involves a significant risk of mortality and morbidity. Data concerning morbidity and mortality risks, however, generally focus on adult donors. Because of the extremely small number of cases involving minor donors, very little is known about the risks for this specific population. Thus, we cannot at present exclude the possibility of the risks being still higher for minor donors.

Future orientation, the third psychosocial factor, also comes into play in living liver donation by minors. Although the regenerative capacity of the liver is often invoked as a reason for dismissing the possibility of any significant future health risks to the donor, such dismissal, at present, seems highly premature. First, living liver donation is too recent a practice for long-term data to have been established. Second, although the donor's liver regains normal metabolic function within a matter of weeks after donation, it regenerates to only approximately $89 \%$ of its preoperative volume. ${ }^{5,39}$ Therefore, we cannot exclude the possibility of the incomplete restoration of the initial liver volume having serious long-term consequences. ${ }^{40}$ Although little is known about the long-term consequences for adult living liver donors, still less is known about the more recent (and extremely smallscale) practice of using minors as living donors. In any case, however, minors are likely to suffer more from any adverse long-term effects because they have a greater number of life years ahead of them.

Most often, impulsivity will not be a salient psychosocial feature of an adolescent's decision to consent to living liver donation. However, in exceptional circumstances, impulsivity might come into play. For example, if the candidate recipient suffers from acute liver failure, he or she might have a life expectancy of less than a week without transplantation. ${ }^{41}$ Under such time pressure, there is an increased chance of the adolescent's impulses getting the upper hand over deliberative, reasoned decision making.

On the basis of this analysis, we may reasonably conclude that many, if not all, of the psychosocial factors feature in the living liver donation decision. We should, therefore, subject this decision to a heightened standard of decisional capacity, that is, one requiring the presence of psychosocial maturity in addition to cognitive maturity. In demanding such a high level of decisional capacity, our proposal satisfies the widely accepted proportionality requirement. The latter refers to a sliding scale and implies that the 
level of decisional capacity required ought to increase in accordance with the level of risk involved in the decision. ${ }^{42}$

As a result of their psychosocial immaturity, adolescents considering living liver donation run the risk of yielding to coercive pressures and placing too little weight on possible immediate and long-term risks. Moreover, under circumstances requiring expedited transplantation, adolescents' decisions are more likely to be rash rather than well thought out. Adolescents should, therefore, be considered incapable of consenting to living liver donation. Thus, in presuming that minors as young as 12 years are able to consent to such a procedure, the Belgian transplantation law is far too permissive.

\section{IS LIVING LIVER DONATION IN THE BEST INTERESTS OF MINORS?}

Because of a minor's insufficient decisional capacity to consent to living liver donation, the harm involved in such a procedure cannot be justified on the basis of his or her autonomous decision. However, the acceptability of living liver donation by minors need not necessarily be ruled out. As noted earlier, parents are generally granted the right to make health care decisions on their minor children's behalf. Although this practice of proxy consent is generally undisputed in cases in which the decision is related to the minor's own health, it is less clear whether it should extend to interventions in minors for the benefit of a third party. ${ }^{43}$ In sum, there may still be grounds in the case of living liver donation to allow parents (or other surrogate decision makers) to give proxy consent.

Those advocating the right of surrogate decision makers to consent to living donation on a minor's behalf disagree about which party is best suited to act as a proxy. Although some argue that the proxy decision should be left to the parents' discretion, others believe that parents might have a conflict of interest. The latter, therefore, recommend transferring the right of decision making to a judge, the minor's physician, or an ethics committee. ${ }^{44}$

When they are making medical decisions for their wards, surrogates are bound by certain standards. There are 2 widely used standards for making decisions on the part of incompetents: the substituted judgment standard and the best interests standard. The former standard dictates that the surrogate act in the way that the patient would if he or she were competent to make the decision. Use of the substituted judgment standard is restricted to those cases for which there is reliable evidence about the patient's preferences for treatment under the circumstances. ${ }^{44}$ We inevitably lack such evidence when we are dealing with patients who have never been competent, such as minors. The best interests standard governs surrogate decision making for this category of incompetents. It requires that the surrogate "determine the highest net benefit among the available options, assigning different weights to interests the patient has in each option and discounting or subtracting inherent risks or costs." 19

As this suggests, the best interest of the incompetent person is the appropriate decision-making standard in the context of living liver donation by minors. Thus, if we grant surrogate decision makers the right to issue proxy consent to donation, their decision must be based on an analysis of the risks and benefits incurred by the minor donor. However, the question remains whether we ought to grant surrogate decision makers this right. After all, it would be foolish to do so and thus allow living liver donation by minors if we have ample reason to believe that this type of donation is generally not in a minor's best interests. Therefore, we now proceed to assess whether living liver donation is generally in a minor's best interests.

Although living donor liver transplantation provides no therapeutic benefit to the donor and carries a high risk of morbidity and mortality, it can still be in the donor's overall best interests if he or she is likely to expect significant psychological benefits. Living organ donors have reported heightened self-esteem, enhanced feelings of autonomy, renewed meaning in life, and other positive feelings associated with important altruistic acts. ${ }^{45,46}$ Combined with the emotional benefits that are more immediately derived from preventing the loss of a loved one, these elements may encourage donation even when considerable health risks are involved. The same type of risk-benefit calculation has been applied to kidney donation by minors to family members. It is argued that minors may already experience the positive effects of altruism and will clearly benefit from the continued companionship of the recipient and from growing up in a family untouched by tragic loss. ${ }^{47,48}$

However, this risk-benefit calculation is problematic when it is applied to minors. For instance, it remains unclear to what extent minors can indeed experience these psychological benefits, especially when their cognitive and emotional capacities are still developing. ${ }^{43,49}$ Furthermore, donation may also have severe negative psychological effects, such as lower self-esteem, feelings of abuse, a strained relationship with the recipient, a sense of neglect and lack of appreciation, and, when transplantation fails, feelings of anger, guilt, and blame. ${ }^{50,51}$ Specifically in liver donation, additional psychological problems have been reported; these include cosmetic issues due to significant scar formation, professional matters resulting from the long recovery time, anxiety regarding one's future health, and, remarkably, a significantly higher rate of psychiatric complications. ${ }^{2,9,52-54}$ Finally, there is yet another sense in which a living liver donor might experience adverse psychological effects. Because minors have generally not yet started families of their own, they may later in life come to regret their decision to donate. After all, despite its regenerative capacity, a liver lobe can be donated only once in a lifetime, and this preempts the opportunity of subsequent donation to people with whom a more intimate bond might exist. ${ }^{55}$ 
In view of the high mortality and morbidity risk, rather speculative psychological benefits, and potentially important psychological risks, we may conclude that living liver donation is generally not in a minor's best interests.

\section{Minor Parent-to-Child Donation: An Exception to the Rule?}

Although living liver donation should not normally be considered as being in a minor's best interests, the possibility of minor parents donating to their own children requires special consideration. Adult parents often describe the decision to donate to their own children as natural and self-evident and emanating from the moral imperative to place the interests of their children before their own. Parents who are not accepted as suitable living donors for their own children often report negative feelings such as disappointment and anger. ${ }^{56}$

The same feelings and experiences are also likely to occur in minor parents. The exceptional nature of the parent-child relationship suggests that a minor parent donating to his or her child will most likely experience a psychological benefit substantial enough to outweigh any negative effects. A uniform prohibition on living liver donation by minors may, therefore, impede minor parents in exercising what they regard as an essential part of their parental responsibility. Thus, minor parent-to-child donation merits consideration as a possible exception to a blanket prohibition on living liver donation by minors. In this respect, it deserves mentioning that in several US states, a minor is generally deemed an unacceptable liver donor unless the intended recipient is his or her own child. ${ }^{57}$ Donation requests from minor parents would always require ad hoc consideration. The specifics of how to deal with such requests, however, lie outside the scope of this article.

\section{CONCLUSIONS}

Living liver donation entails an invasive procedure with fairly high risks of morbidity and mortality. Donation by minors is acceptable only when the procedure is the result of informed, well-considered, and autonomous consent by the potential minor donor or when it is in the minor's best interests. We have argued that minors should not be regarded as having sufficient decisional capacity to consent to living liver donation. Although adolescents possess sufficient cognitive maturity, they lack sufficient psychosocial maturity to resist family pressure and impulsivity and to fully take into account possible immediate and long-term risks. In addition, living liver donation by minors cannot be justified on the basis of the best interests of the minor because current knowledge regarding the psychological benefits of living liver donation by minors is inadequate. Moreover, if we presume that a minor may experience psychological benefits as a result of living liver donation, these benefits are unlikely to outweigh the medical and psychological risks and burdens of the procedure. It is only in the case of a minor parent donating to his or her child that the benefits are likely to outweigh the risks. Therefore, we conclude that, with the possible exception of minor parents donating to their children, minors should not be considered as potential living liver donors.

\section{REFERENCES}

1. Renz JF, Yersiz H, Farmer DG, Hisatake GM, Ghobrial RM, Busuttil RW. Changing faces of liver transplantation: partial-liver grafts for adults. J Hepatobiliary Pancreat Surg 2003;10:31-44.

2. Barr ML, Belghiti J, Villamil FG, Pomfret EA, Sutherland DS, Gruessner RW, et al. A report of the Vancouver Forum on the care of the live organ donor: lung, liver, pancreas, and intestine data and medical guidelines. Transplantation 2006;81:1373-1385.

3. Kousoulas L, Becker T, Richter N, Emmanouilidis N, Schrem H, Barg-Hock H, et al. Living donor liver transplantation: effect of the type of liver graft donation on donor mortality and morbidity. Transpl Int 2011;24:251258.

4. Otte JB. Donor complications and outcomes in live-liver transplantation. Transplantation 2003;75:1625-1626.

5. Middleton PF, Duffield M, Lynch SV, Padbury RT, House $\mathrm{T}$, Stanton $\mathrm{P}$, et al. Living donor liver transplantationadult donor outcomes: a systematic review. Liver Transpl 2006; 12:24-30.

6. Graziadei IW. Living donor liver transplantation. Trop Gastroenterol 2007;28:45-50.

7. Dutkowski P, De Rougemont O, Müllhaupt B, Clavien PA. Current and future trends in liver transplantation in Europe. Gastroenterology 2010;138:802-809.e1-e4.

8. Brown RS Jr, Russo MW, Lai M, Shiffman ML, Richardson MC, Everhart JE, Hoofnagle JH. A survey of liver transplantation from living adult donors in the United States. N Engl J Med 2003;348:818-825.

9. Renz JF, Roberts JP. Long-term complications of living donor liver transplantation. Liver Transpl 2000;6(suppl 2):S73-S76.

10. Brown RS, Weisberg IS. Current and future trends in liver replacement therapy. US Gastroenterology \& Hepatology Review 2007;2:53-54.

11. Trotter JF, Wachs M, Everson GT, Kam I. Adult-to-adult transplantation of the right hepatic lobe from a living donor. N Engl J Med 2002;346:1074-1082.

12. Ladd RE. The child as living donor: parental consent and child assent. Camb Q Healthc Ethics 2004;13:143-148.

13. Organ Procurement and Transplantation Network. http:// optn.transplant.hrsa.gov. Accessed February 2013.

14. Honda N, Awata S, Matsuoka H. The case of a living liver donor who was underage: psychiatric issues and evaluation [in Japanese]. Seishin Shinkeigaku Zasshi 2009; 111:930-937.

15. Tannuri AC, Gibelli NE, Ricardi LR, Santos MM, Maksoud-Filho JG, Pinho-Apezzato ML, et al. Living related donor liver transplantation in children. Transplant Proc 2011;43:161-164.

16. Federale Overheidsdienst Justitie. Amendment of Belgian transplantation law. http://www.ejustice.just.fgov.be/ doc/rech_n.htm. Accessed February 2013.

17. Veatch RM. Transplantation Ethics. Washington, DC: Georgetown University Press; 2000.

18. Gutmann T, Land WG. The European perspective. In: Gruessner RWG, Benedetti E, eds. Living Donor Organ 
Transplantation. New York, NY: McGraw-Hill; 2008:3742.

19. Beauchamp TL, Childress JF. Principles of Biomedical Ethics. 6th ed. New York, NY: Oxford University Press; 2009.

20. Boonstra H, Nash E. Minors and the right to consent to health care. Issues Brief (Alan Guttmacher Inst) 2000:16.

21. Derish MT, Heuvel KV. Mature minors should have the right to refuse life-sustaining medical treatment. J Law Med Ethics 2000;28:109-124.

22. Driggs AE. The mature minor doctrine: do adolescents have the right to die? Health Matrix Clevel 2001;11:687717.

23. Stultiëns L, Goffin T, Borry P, Dierickx K, Nys H. Minors and informed consent: a comparative approach. Eur J Health Law 2007;14:21-46.

24. Sanci LA, Sawyer SM, Weller PJ, Bond LM, Patton GC. Youth health research ethics: time for a mature-minor clause? Med J Aust 2004;180:336-338.

25. Schlam L, Wood JP. Informed consent to the medical treatment of minors: law and practice. Health Matrix Clevel 2000;10:141-174.

26. Toner K, Schwartz R. Why a teenager over age 14 should be able to consent, rather than merely assent, to participation as a human subject of research. Am $\mathrm{J}$ Bioeth 2003;3:38-40.

27. Steinberg L, Scott ES. Less guilty by reason of adolescence: developmental immaturity, diminished responsibility, and the juvenile death penalty. Am Psychol 2003;58:1009-1018.

28. Weithorn LA, Campbell SB. The competency of children and adolescents to make informed treatment decisions. Child Dev 1982;53:1589-1598.

29. Hale S. A global developmental trend in cognitive processing speed. Child Dev 1990;61:653-663.

30. Belter RW, Grisso T. Children's recognition of rights violations in counseling. Prof Psychol Res Pract 1984; 15:899-910.

31. Steinberg L, Cauffman E, Woolard J, Graham S, Banich M. Are adolescents less mature than adults?: minors' access to abortion, the juvenile death penalty, and the alleged APA "flip-flop". Am Psychol 2009;64:583-594.

32. Gardner M, Steinberg L. Peer influence on risk taking, risk preference, and risky decision making in adolescence and adulthood: an experimental study. Dev Psychol 2005;41:625-635.

33. Ponton LE. The Romance of Risk. Why Teenagers Do the Things They Do. New York, NY: Basic Books; 1997.

34. Cauffman E, Steinberg L. (Im)maturity of judgment in adolescence: why adolescents may be less culpable than adults. Behav Sci Law 2000; 18:741-760.

35. Halpern-Felsher BL, Cauffman E. Costs and benefits of a decision: decision-making competence in adolescents and adults. J Appl Dev Psychol 2001;22:257-273.

36. Larson R, Csikszentmihalyi M, Graef R. Mood variability and the psychosocial adjustment of adolescents. J Youth Adolesc 1980;9:469-490.

37. Farrington DP. Developmental and life-course criminology: key theoretical and empirical issues-the 2002 Sutherland Award address. Criminology 2003;41:221255.
38. Wendler DS. Assent in paediatric research: theoretical and practical considerations. J Med Ethics 2006;32:229234.

39. Haga J, Shimazu M, Wakabayashi G, Tanabe M, Kawachi $\mathrm{S}$, Fuchimoto $\mathrm{Y}$, et al. Liver regeneration in donors and adult recipients after living donor liver transplantation. Liver Transpl 2008;14:1718-1724.

40. Pomfret EA. Early and late complications in the rightlobe adult living donor. Liver Transpl 2003;9(suppl 2):S45-S49.

41. Stravitz RT, Kramer DJ. Management of acute liver failure. Nat Rev Gastroenterol Hepatol 2009;6:542-553.

42. Doig C, Burgess E. Withholding life-sustaining treatment: are adolescents competent to make these decisions? CMAJ 2000; 162:1585-1588.

43. Schenberg BA. Harvesting organs from minors and incompetent adults to supply the nation's organ drought: a critical review of the substituted judgment doctrine and the best interest standard. Indiana Health Law Rev 2007;4:319-358.

44. Nygren SL. Organ donation by incompetent patients: a hybrid approach. Univ Chic Legal Forum 2006:471-502.

45. Johnson EM, Anderson JK, Jacobs C, Suh G, Humar A, Suhr BD, et al. Long-term follow-up of living kidney donors: quality of life after donation. Transplantation 1999;67:717-721.

46. Patenaude AF. Psychological impact of bone marrow transplantation: current perspectives. Yale J Biol Med 1990;63:515-519.

47. Hart v Brown, 289 A 2d 386 (Conn Sp Ct 1972).

48. Little v Little, 576 SW 2d 493 (Tex Ct App 1979).

49. Crouch RA, Elliott C. Moral agency and the family: the case of living related organ transplantation. Camb $Q$ Healthc Ethics 1999;8:275-287.

50. Cheyette C. Organ harvests from the legally incompetent: an argument against compelled altruism. Boston Coll Law Rev 2000;41:465-515.

51. Packman WL, Crittenden MR, Schaeffer E, Bongar B, Fischer JB, Cowan MJ. Psychosocial consequences of bone marrow transplantation in donor and nondonor siblings. J Dev Behav Pediatr 1997; 18:244-253.

52. Cipe G, Tuzuner A, Genc V, Orozakunov E, Ozgencil E, Yilmaz AA, et al. Living-donor hepatectomy. Transplant Proc 2011;43:888-891.

53. Erim Y, Beckmann M, Valentin-Gamazo C, Malago M, Frilling A, Schlaak JF, et al. Quality of life and psychiatric complications after adult living donor liver transplantation. Liver Transpl 2006;12:1782-1790.

54. Trotter JF, Hill-Callahan MM, Gillespie BW, Nielsen CA, Saab S, Shrestha R, et al.; for A2ALL Study Group. Severe psychiatric problems in right hepatic lobe donors for living donor liver transplantation. Transplantation 2007;83:1506-1508.

55. Holm S. The child as organ and tissue donor: discussions in the Danish Council of Ethics. Camb 8 Healthc Ethics 2004; 13:156-160.

56. Zeiler K, Guntram L, Lennerling A. Moral tales of parental living kidney donation: a parenthood moral imperative and its relevance for decision making. Med Health Care Philos 2010;13:225-236.

57. Brown RS Jr. Live donors in liver transplantation. Gastroenterology 2008;134:1802-1813. 